\title{
ПСИХОЛОГИЧЕСКОЕ СОДЕРЖАНИЕ, СООТНОШЕНИЕ И НАУЧНОЕ ПРИМЕНЕНИЕ КОНЦЕПТОВ «LOYALTY» И «COMMITMENT»
}

\author{
C.B. ГОРНОСТАEB ${ }^{\mathrm{a}}$
}

${ }^{a}$ Академия ФСИН России, 390000, Россия, Рязань, ул. Сенная, д. 1

\begin{abstract}
Резюме
В рамках решения проблемы содержательной неопределенности и нечеткости понятия «лояльность» в статье подчеркнута необходимость его дифференциации с сопряженными и смежными понятиями. Проведен сравнительный анализ часто смешиваемых терминов «loyalty» и «commitment». Проанализирована возможность экстраполяции полученных результатов на соотношение русскоязычных терминов «лояльность» и «приверженность». Рекомендованы следующие правила научного применения сравниваемых терминов: 1) термин «лояльность» логично употреблять только в контексте личностно-групповых отношений, а термин «приверженность» - и за его пределами; 2) термин «лояльность» применим лишь для указания на отношения типа «субъект-субъект», что возможно в отношениях личности с группами членства, характеризующимися реальным психоповеденческим единством, а термин «приверженность» применим для указания на отношения типа «субъект-объект» применительно к любым группам; 3) термин «лояльность» применим при рассмотрении соотношения личности с группой как с системой во всех ее взятых в единстве психоповеденческих аспектах, термин «приверженность», применяемый в личностногрупповом контексте, может отражать отношение человека к отдельным характеристикам группы; 4) в психологическом аспекте термин «лояльность» уместнее использовать, чтобы охарактеризовать личность в целом, а термин «приверженность» - чтобы охарактеризовать ее отдельные особенности; 5) указывая на проявления тотальной регуляции поведения нормами группы самоидентификации и фактического членства, рекомендуется употреблять термин «лояльность», а термин «приверженность» лучше подходит при описании поступков, связанных с отдельными выборами и решениями человека, не отражающими направленность личности и социальную самоидентификацию. Отмечена актуальность термина «лояльность» для системных концептуальных исследований личности в группе, а термина «приверженность» - для прикладных исследований конкретных форм социального поведения.
\end{abstract}

Ключевые слова: лояльность, приверженность, социальная система, группа, личность. 


\section{Проблема смешения понятий в исследованиях лояльности}

Исследования лояльности - одно из современных направлений изучения личности в группе. Многочисленность посвященных этой проблеме работ и обилие полученных эмпирических результатов создают иллюзию ее разработанности. Однако анализ литературы показывает, что многочисленные исследования до сих пор проводятся в отсутствие общенаучной концепции лояльности, отражающей сущностные инвариантные характеристики феномена и объединяющей различные направления и отрасли его изучения единой проблематикой. В настоящий момент не сложилось четкого представления даже о сути феномена лояльности (Баранская, 2012; Бобрус, 2009; Доминяк, 2006; Thornberry, 2003; и др.). Поэтому в проводимых исследованиях термин «лояльность», как отмечал еще А. Коренблюм, зачастую используется в «повседневном, описательном, народном смысле, а не как понятие, имеющее какое-то особое и точное значение в теоретической схеме» (Corenblum, 1964, p. 2). Из-за отсутствия четкости понимания и использования термина «лояльность», как и многих сопряженных терминов («приверженность», «верность», «преданность» и др.), не только в повседневном использовании, но и в научных исследованиях лояльности наблюдаются смешение и подмена понятий. В отечественной науке эта проблема ранее отмечалась, например, Н.В. Серковой, указавшей на безосновательную подмену в исследованиях понятия «преданность» понятием «лояльность» (Серкова, 2004). С.А. Липатовым отмечается смешение целой группы содержательно близких с лояльностью понятий (Липатов, 2004).

В итоге затруднительно определить круг релевантных проблеме исследований, сопоставить, обобщить или адекватно применить их результаты. Вышеизложенное указывает на необходимость определения и последующей четкой дифференциации понятия «лояльность» с сопряженными и смежными концептами.

Феномен лояльности до последних десятилетий не являлся предметом отечественных исследований, и проблема подмены понятия лояльности отражает зарубежные тенденции, поэтому в первую очередь необходим анализ соотношения термина «лояльность» (loyalty) и сопряженных терминов в зарубежной литературе.

Проведенный анализ публикаций позволил прийти к выводу, что в зарубежных исследованиях чаще всего термин «лояльность» (loyalty) смешивается с термином «commitment» (приверженность, обязательство).

\section{Состояние проблемы соотношения понятий «loyalty» и «commitment»}

Попытки разведения понятий «loyalty» и «commitment» предпринимались и ранее. Однако анализ чаще затрагивал лишь отдельные аспекты их соотношения и связи (Fullerton, 2003; Maheshwari et al., 2014; и др.). Либо он проводился слишком поверхностно и все равно не выявлял ключевых сущностных различий феноменов. Так, А. Икбал, С. Туфаил и Р. Лодхи (Iqbal et al., 2015) в результате анализа практики применения слов «loyalty» и «commitment» пришли 
к выводу, что они схожи по содержанию, но словом «loyalty» чаще пользуются, указывая на психологическое содержание явления, a «commitment» - на его поведенческий аспект. В.И. Доминяк (2006) и вслед за ним Г.А. Стародубцева (2012) сводят различия терминов «loyalty» и «commitment» к тому, что один из них используется в популярной литературе, а другой - в научной.

Разведение данных понятий в отечественной науке осложняется искажениями, возникающими при некорректном переводе и фрагментарном цитировании работ зарубежных авторов. В отсутствие переводов немногочисленных фундаментальных работ по теории лояльности, позволяющих выделить сущность феномена, отечественные исследователи проблем лояльности зачастую работают с предположениями и допущениями, принятыми без достаточных научных оснований. Так, большинство отечественных исследователей, следуя традиции, заложенной В.И. Доминяком, и используя зарубежные работы, рассматривают содержащиеся в них концепты «loyalty» и «commitment» как синонимы. Хотя, например, Н. Аллен и Дж. Мейер, на базе концепции которых построено большинство отечественных исследований, сблизив эти понятия, все же не отождествляли их (Meyer, Allen, 1997). Условность рассмотрения анализируемых терминов как синонимов отмечается и самими исследователями (см., например: Антонова, 2017; Доминяк, 2006). Однако именно исходя из этого допущения, формируются теоретические концепции и модели, которые в итоге остаются достаточно запутанными, особенно в части соотношения лояльности и приверженности. Например, Е.Л. Трофимова и В.Ю. Бондаренко в ходе изучения соотношения лояльности и приверженности, анализируя концепцию Н. Аллен и Дж. Мейера, переводят использованный в первоисточнике термин «commitment» сначала как «приверженность», а затем на той же странице как «лояльность» (Трофимова, Бондаренко, 2013, c. 31). М.А. Лячин и О.Е. Подвербных сначала прямо указывают на синонимичность лояльности и приверженности (Лячин, Подвербных, 2017, с. 190), а затем, в той же работе заключают, что лояльность является частью приверженности (Там же, с. 193). Я.В. Берлизева приходит в итоге к обратному выводу о том, что приверженность «представляет собой “венец” интегральной модели лояльности» (Берлизева, 2013, с. 176), является ее высшей формой, хотя в начале работы также выражает мнение о синонимичности использования терминов в зарубежной литературе, на которой построен анализ. Подобные примеры не единичны, они отражают недостаточную четкость понимания анализируемых теоретических концептов и их различий. Ситуация усугубляется попытками ряда ученых опереться при построении своих научных концепций на доступные источники популярного характера, содержащие определения лояльности, произвольно данные их авторами в ключе интуитивно-бытового подхода, без надлежащего учета имеющихся результатов научно-концептуальных исследований феномена.

Наиболее серьезная попытка решения проблемы соотношения сущности концептов «loyalty» и «commitment», на наш взгляд, была предпринята P. Куланом (Coughlan, 2005). Он отметил, что важнейшим источником лояльности является интериоризация групповых ценностей, а не ожидание стимулов 
со стороны, приводящее к подстройке поведения под требования социально окружения (compliance) и играющее главную роль в формировании приверженности. Основное отличие лояльности даже от «нормативной приверженности» Н. Аллен и Дж. Мейера, которую Р. Кулан считал наиболее близким феноменом, ученый видел в том, что приверженность, как правило, регулирует одно-единственное конкретное действие или аспект поведения - например, продолжение работы в организации - в отличие от лояльности, проявляющейся в реализации воспринятой системы групповых принципов правильного поведения во всех аспектах и ситуациях групповой активности.

Отмечая научность подхода Р. Кулана и его стремление выделить наиболее общие, сущностные различия анализируемых феноменов, выходящие за пределы конкретной отрасли знаний, необходимо констатировать недостаточность полученных им результатов в связи с ограничениями предложенной данным ученым концепции лояльности. Его понимание лояльности как добровольного разделения общегрупповых моральных принципов, регулирующих активность членов группы причастности, отражает социально-психологическую суть феномена, однако оно является зауженным по сравнению с аргументированными ранее представлениями о лояльности, включающими вопросы самоидентификации, групповых эмоций и соответствия групповым ожиданиям в деталях поведения (Boszormenyi-Nagy, Spark, 1973; Fletcher T.W., 1958; Fletcher G.P., 1993; Grodzins, 1956; Rogers, 1918; Royce, 1908; и др.).

Таким образом, вопрос соотношения содержания концептов «loyalty» и «commitment» представляется неразрешенным, что затрудняет понимание содержания зарубежных первоисточников по теории лояльности и препятствует упорядочиванию научного применения русскоязычных аналогов данных терминов. Решение указанного вопроса будет способствовать уточнению сущности феномена, определению круга релевантных проблеме лояльности исследований, обеспечению сопоставимости полученных в различных областях ее исследований научных результатов, а в итоге - переходу от фрагментарных к системным исследованиям лояльности.

\section{Историко-лингвистический и содержательно-психологический анализ концептов «loyalty» и «commitment»}

До XX в. слова «loyalty» и «commitment» не использовались синонимично.

Слово «лояльность» (loyauté), впервые встречается в старофранцузском языке и происходит от старофранцузского «loi» - аналога латинского «lex» (закон, правило, норма, порядок, договор) (Boszormenyi-Nagy, Spark, 1973). В средневековый период становления сословных норм, преимущественно имевших форму обычаев, и практики деятельности сословных судов «лояльность» понималась как соответствие жизненным (преимущественно неписаным) нормам своего сословия, профессионального или территориального сообщества (Горностаев, 2017). Распространенное в период Нового времени в староанглийском языке слово «лояльность» (loyaltie) подразумевало также и соответствующее эмоциональное отношение к групповым символам (например, к фигуре, но 
не личности монарха). В доконцептуальных исследованиях проблемы лояльности на рубеже XIX-XX вв. она рассматривалась в аспекте интеграции человека в группу, социальной идентичности и ее влияния на активность личности. Такое понимание задало направление концептуальным исследованиям феномена, начатым Дж. Ройсом, но впоследствии было размыто за счет отрыва эмпирических исследований от концептуальных, обособления и изоляции отраслевых исследований лояльности, что привело не к кристаллизации общенаучной концепции лояльности, а к бессистемному накоплению массива слабо связаных данных.

В результате проведенного теоретико-эмпирического анализа (Там же) было выделено психологическое содержание феномена лояльности, сформулированное в ряде позиций:

1. Лояльность - системное социально-психологическое явление, не существующее вне социальных групп и носящее трансличностный характер.

2. Лояльность можно определить как причастность личности к группе на взаимосвязанных уровнях самоопределения, групповых эмоций, а также мотивации, направленности и процессов групповой активности.

3. Лояльность репрезентуется в индивидуальной психике и одновременно регулируется этой репрезентацией. Ключевыми эмпирическими компонентами индивидуальной психической репрезентации лояльности являются: 1) удовлетворенность пребыванием в группе; 2) воспринятое мотивационное сходство; 3) осознанное принятие членства и 4) осознание включенности в групповые процессы. Данные компоненты находятся в системном единстве и детерминируют друг друга.

4. Наиболее значимые и универсальные психологические механизмы их взаимосвязи, обеспечивающие функционирование лояльности на индивидуально-психологическом уровне: 1) стремление к деятельностно-статусному соответствию; 2) интрапсихическое взаимоиндуцирование когнитивной и эмоциональной групповой самоидентификации; 3) взаимостимулирование оценок личных вкладов в общую деятельность и позитивных откликов на них группы.

5. Факторами, к которым наиболее чувствительны указанные компоненты, соответственно выступают: 1) принятие личности группой; 2) вербальная и невербальная трансляция другими членами группы знаков и символов, ассоциирующихся с собственными ключевыми идентичностями, убеждениями, ценностями, целями и ведущей деятельностью; 3) наличие очевидных, социально разделяемых оснований обособления группы и критериев принадлежности к ней; 4) сформированность групповых ожиданий в отношении члена группы.

Наполнение термина «лояльность» (loyalty) конкретно-психологическим содержанием позволило обоснованно сравнить его с концептом «commitment» (приверженность, обязательство).

Как свидетельствует анализ источников, размещенных на сайте «Early English Books Online» (https://corpus.byu.edu/eebo), слово «commitment» вплоть до ХХ в. в наиболее общем смысле обозначало вверение или передачу во власть чего-либо или нахождение во власти чего-либо, вплоть до тюремного заключения. 
В начале XX в. встречаются упоминания термина «commitment» в социально-психологическом смысле, как, например, посвящение себя определенной культуре, ценностям и жизненному пути (см., например: N/A, 1921).

Ко второй половине XX века за словом «commitment» закрепляется значение «обязательство», не только в смысле вмененных или естественно возникших, но и добровольно принятых на себя обязательств.

Х. фон Вригт, рассматривая природу обязательств, указал на зависимость последующих действий от ранее совершенных, возникающую благодаря системе разделяемых норм и моральных принципов, закрепляющих такую зависимость (von Wright, 1951). Ученый писал: «Дача обещания и неследование ему - два морально несовместимых акта. Совершение одного акта обязывает (commits) нас совершать другой, если их связь обязательна» (Ibid., p. 4). Тем самым он указал на невозможность возникновения обязательств вне системы психоповеденческих норм, разделяемых людьми и их объединяющих. Данная идея послужила серьезным шагом к рассмотрению конструктов «loyalty» и «commitment» как сопряженных.

Развитию этой идеи послужили исследования Б. Мейо, который выделил три типа обязательств: обещания (promises), договоры (contracts) и долги (debts) (Мауо, 1955). Анализируя мотивационную основу обязательств как осознания необходимости выполнения определенных действий, он полагал, что ее составляет признание личностью связи между определенным совершенным им действием, формы которого могут различаться (например: обещание себе, публичная клятва или символическое действие, демонстрирующее причастность к какой-либо группе), и вытекающими из него обязательствами.

И. Босормени-Надь и Дж. Спарк, исходя из позиции, что лояльность «скорее системная сила, чем расположенность личности» (Boszormenyi-Nagy, Spark, 1973, p. 53), рассмотрели обязательства как составляющую лояльности, под которой они понимали систему определяющих друг друга психологической принадлежности и включенности в функционирование социальной группы. Они отмечали, что активность лояльных членов группы соответствует закрепленному в групповых ожиданиях порядку, включающему наиболее общие обязательства, которые конкретно проявляются и усложняются на межличностном уровне.

Авторы выделили в системах лояльности обязательства: 1) по отношению к системе; 2) сформировавшиеся в отношении отдельных членов группы; 3) обязательства во взаимоотношениях со значимыми для социальной системы, но не включенными в нее объектами.

И. Босормени-Надь и Дж. Спарк указали, что «неизменное выживание системы - контекстная цель взаимных ожиданий, обязательств и лояльности» (Ibid., p. 4); «самые фундаментальные обязательства, вытекающие из лояльности (loyalty commitments), относятся к поддержке существования группы как таковой» (Ibid., p. 5).

Частные особенности структуры и характера обязательств в каждой системе лояльности определяются, как писали И. Босормени-Надь и Дж. Спарк, через баланс заслуг и долгов, гордости и вины отдельных членов социальной системы, а также экзистенциальную общечеловеческую справедливость. 
По их мнению, обязательства, будучи психологически более простым типом человеческих взаимосвязей, могут существовать и вне лояльности. Лояльность же не может существовать без обязательств. Ученые считают, что «система отношений удерживается в целости балансом обязательств между ее членами» (Ibid., р. 18). «Обязательства, вытекающие из лояльности, - как невидимые, но сильные нити, которые скрепляют сложные части родственного поведения в семьях так же, как в большем обществе» (Ibid., p. 39). Однако лояльность, по мнению авторов,- это всегда больше чем набор обязательств, которые теряют свой смысл вне групповых целей, принципов, символических значений, духа групповых ожиданий и системы групповых отношений. Авторы указали, что лояльность, кроме обязательств, включает в себя идентификацию с группой, подлинную связанность объекта с другими членами, доверие и многие другие компоненты.

Таким образом, в понимании «обязательство» термин «commitment» в контексте социальных групп может быть сопряжен с термином «loyalty, но отличается от него по содержанию.

В работах ряда авторов начиная с 1950-х гг. термин «commitment» использовался также в значении, сопоставимом со словом «приверженность», в том числе применительно и к различным группам (см., например: Simon at al., 1950; Coleman, 1957; Gouldner, 1960; и др.).

Концепцию приверженности, содержательно близкую к изложенной нами концепции лояльности, предложила Х. Гаулднер, рассмотрев тот вид приверженности формальным организациям (organizational commitment), которая обусловлена «собственными мотивами, ориентирами и поведением человека» (Gouldner, 1960, p. 469). Она отметила такие формы приверженности организациям, как «космополитическая интеграция - степень, в которой человек является включенным в активность и чувствует себя частью различных уровней отдельной организации, при активности также в других организациях; и организационная интроекция - степень, в которой «идеальный» Я-образ человека включает множество одобряемых организацией качеств и ценностей» (Ibid., p. 468). Очевидно, предложенные X. Гаулднер критерии приверженности организации (включенность в активность группы, идентификация с ней и стремление к ее идеалам) можно сопоставить с психологическим содержанием лояльности.

Однако Х. Гаулднер вслед за Х. Саймоном, Д. Смитбургом, В. Томпсоном и Дж. Коулменом выделяет различные виды приверженности - приверженность организации как группе людей и приверженность конкретным ценностям и идеалам организации, эмпирически доказывая в своей работе наличие различий между ними (Gouldner, 1960). Для оценки приверженности организации в целом X. Гаулднер выделяет различные параметры активности участия в деятельности организации (предпочтение организации другим организациям, готовность отказаться от времяпровождения в других группах, чтобы поддерживать нынешний уровень активности в организации, и т.п.). Критериями приверженности ценностям организации в отличие от приверженности ей самой Х. Гаулднер считает стремление человека строить в соответствии с этими ценностями свое поведение и позитивное восприятие осуществляемого в соответствии с ними поведения других. 
Возможность такого разделения противоречит предложенной нами концепции лояльности, в соответствии с которой группа лояльности является ценной для личности, поскольку разделяет и позволяет реализовывать значимые для человека ценности и идеалы. Единство предмета и объекта лояльности - группы и основ ее объединения в данном случае выступает критерием, позволяющим дифференцировать концепт лояльности от концепта приверженности в понимании X. Гаулднер, предполагающей возможность отдельно взятой приверженности человека либо к конкретной социальной структуре, либо к объединяющей ее идее.

X. Гаулднер, указывая на существование многих вариантов личностногрупповых связей, понимает приверженность (commitment) как не самый тесный из них «in but not of the organization» (Ibid., p. 483), носящий субъект-объектный характер. А лояльность подразумевает рассмотрение человека в качестве части социальной системы, одновременно и зависимой от системы, и влияющей на нее, рассмотрение человека не просто как взаимодействующего с социальной системой, но и как во всех смыслах включенного в нее, представляющего ее.

Исходя из положений Х. Гаулднер, можно заключить, что приверженность является более простой в психологическом смысле формой связи человека с группой, как в плане содержания, так и в плане уровня системной организации ее структурных компонентов.

Значительное влияние на содержание научного понятия «commitment» оказала концепция Г. Беккера. Он выделял акты или состояния приверженности (acts or states of commitment), ассоциируя приверженность со стабильностью реализации ранее сформировавшегося у человека мотива, в том числе и в ситуациях, влияющих на реализацию этого мотива лишь косвенно (Becker, 1960). Приверженность, по Г. Беккеру, предполагает обусловленную предыдущими жизненными событиями, выборами и действиями устойчивую линию поведения, формируемую и поддерживаемую ее личностным смыслом.

Г. Беккер рассматривает как один из главных психологических механизмов приверженности «side bet» - вовлечение в ситуацию своих интересов, не связанных с ситуацией изначально и постоянно, но достаточно значимых, чтобы уход от избранной линии поведения в пользу альтернатив перестал рассматриваться всерьез.

По мнению Г. Беккера, приверженность объясняет неизменное, постоянное поведение, которое сохраняется длительное время, предполагает достижение целей и отказ от возможных реальных вариантов, имеющих свои преимущества.

Г. Беккер выделил следующие признаки приверженности: 1) деятельность в конкретной ситуации может повлиять на интересы и управляется интересами, которые не всегда связаны с подобными ситуациями; 2) человек поставлен в сложившуюся ситуацию своими предыдущими действиями; 3) приверженное лицо осознает, что привлекает не относящиеся к ситуации мотивы (made a side bet) и что его решение будет иметь различные варианты (ramification) последствий. Осознание интересов, созданных предыдущими действиями, является необходимым, потому что человек не будет действовать для реализации этих побочных интересов (side bet), пока он их не осознает. 
Активность, являющаяся следствием приверженности, неразрывно связана с осознанием ее предполагаемых последствий. Однако формироваться приверженность может и неосознанно, в результате решений или действий, ведущих к формированию и осознанию того или иного мотива, достаточно влиятельного, чтобы подчинить себе поведение во всех ситуациях, связанных с его реализацией.

Г. Беккер полагал, что удобно использовать термин «приверженность» для явлений, вызванных механизмом предварительного создания побочных интеpeсов (previously placed side bet), и другие термины для подобных, но отличающихся феноменов.

Как и в концепции вынужденных линий поведения (committed lines) (Abramson et al., 1958), в основе концепции приверженности Г. Беккера лежит понимание если не вынужденности, то подвластности «приверженного» поведения доминирующим интересам личности, реализуемым с учетом ситуации. Это понимание определяет в целом современные взгляды на феномен приверженности. С учетом позиций Г. Беккера существенными отличиями приверженности от лояльности являются следующие: 1) обязательное наличие осознания и волевых усилий в реализации избранной линии поведения; 2) ориентация приверженных лиц на конкретные формы поведения, а не на ценности, с которыми они обычно связаны, «вынужденность» в этом смысле реализуемых форм поведения; 3) отделение себя от объекта приверженности, отсутствие самоидентификации с ним; 4) опосредованность связи реализуемой в рамках приверженности линии поведения с доминирующей мотивацией и направленностью личности.

Отдельные положения сближают концепцию приверженности, которую предложили Ч. Орейли и Дж. Четмен (O’Reilly, Chatman, 1986), с пониманием лояльности, изложенным выше. Ч. Орейли и Дж. Четмен считали приверженность основой чувства привязанности (attachment), отражающего степень интернализации или принятия характеристик и перспектив организации. По мнению авторов, это чувство базируется на таких факторах, как: 1) идентификация, основанная на желании аффилиации; 2) интернализация, основанная на совпадении личных и организационных ценностей; 3) конформность (compliance), основанная на восприимчивости к специфическим внешним подкреплениям. Внешним критерием изучаемого феномена Ч. Орейли и Дж. Четмен считали поведение, соответствующее статусу члена организации (organizational citizenship behavior). Несмотря на то что в своей концепции Ч. Орейли и Дж. Четмен используют конструкты, включаемые нами в содержание лояльности, эти ученые рассматривают их не как составляющие, а как факторы анализируемого ими феномена, также не предполагая их системного единства, характерного для лояльности. Они рассматривают их не как часть феномена, а лишь как отдельные предпосылки конечного результата - привязанности.

В большинстве современных концепций приверженности, в том числе и наиболее популярной, которую разработали Дж. Мейер и Н. Аллен, анализируемые концепты не сравниваются напрямую, но при этом очевидны разли- 
чия в их применении. Например, указанные ученые употребляли слово «соmmitment» для обозначения каких-то конкретных видов предметов и механизмов «привязанности» человека к группе, а также запускающих и поддерживающих их внешних факторов. Слово «loyalty» авторы употребляли как многоаспектный, обобщающий и более абстрактный термин, скорее указывающий на наличие факта личностно-групповых отношений, чем на их особенности (Meyer, Allen, 1997).

Описывая результаты лингвистического анализа современного значения слова «commitment», проведенного Р. Брауном (Brown, 1996), В.И. Доминяк следующим образом передает результаты проведенного Р. Брауном анализа: «Термин обычно используется для описания “состояния кого-то, кто решительно согласился с некоторой другой стороной в связи с некоторым будущим событием" <...> "Commitment” определяется как состояние “быть обязанным или связанным (как интеллектуальным убеждением, так и эмоциональными связями)” (Brown, 1996; цит. по: Доминяк, 2006, с. 17).

В итоге интегративного анализа научных подходов к содержанию концепта «commitment» А. Коэн пришел к выводу, что в наиболее общем смысле под этим термином понимается «сила, которая привязывает человека к линии поведения, обеспечивающей достижение одной или нескольких целей» (Cohen, 2003, p. хі). Он подчеркивает разнообразие сил, различие в характере факторов и психологических механизмов, обеспечивающих подобную привязку, а основную проблему изучения приверженности сводит к их систематизации и измерению. Вместе с тем отмечается акцентированность исследований на внешне наблюдаемой поведенческой результирующей действия различных внутренних психологических сил, ассоциируемой с термином «commitment» в рамках так называемого «поведенческого» подхода. На наш взгляд, А. Коэн выразил суть общенаучного содержания термина «commitment» достаточно точно.

Анализ литературы показал, что употребление термина «commitment» действительно чаще подчеркивает интерес исследователей к итоговым поведенческим проявлениям, а детерминирующие их психологические механизмы и факторы чаще рассматриваются как переменная в исследованиях и не составляют сущностного содержания феномена.

Таким образом, содержание понятия «commitment», в социально-психологическом контексте обычно обозначающего «обязательство» или «приверженность», не соответствует приведенному выше содержанию концепта «loyalty» (лояльность).

\section{Оценка применимости полученных результатов в отечественных исследованиях и рекомендации по использованию терминов «лояльность» и «приверженность»}

Целесообразность применения вышеизложенных результатов в отечественной науке и практике определяется сравнительной развитостью зарубежных исследований проблем лояльности и достаточным содержательным 
сходством терминов «loyalty» и «commitment» с русскоязычными терминами «лояльность» и «приверженность».

В русском языке смысл слова «лояльность» является таким же расплывчатым, как и в английском. В различных социальных контекстах его используют как синоним послушания, снисходительности, доброжелательности, толерантности и др. Широчайший спектр значений слова «лояльность» включает в себя, казалось бы, несовместимые смыслы, например, попустительство и ревностное участие. Даже в одном и том же контексте термин несет различные значения (например, в иерархических группах лояльность начальников ассоциируется со снисхождением, а подчиненных - с послушанием).

При подобной широте и разнообразии применения термина «лояльность», как обыватели, так исследователи зачастую упускают трансконтекстные сущностные характеристики феномена. Основоположник концептуальных исследований лояльности Дж. Ройс связывал эту ошибку с тем, что людям трудно абстрагироваться от конкретного социального контекста применения понятия, «освободить идею от несущественного, навязанного устойчивыми ассоциациями с теми или иными социальными стереотипами и обстоятельствами» (Royce, 1908, p. viii).

Анализ употребления термина «лояльность» все же позволяет выделить массив его значений, преимущественно сосредоточенных вокруг позитивного или нейтрального эмоционального отношения и нормативности поведения в социальном взаимодействии. Можно обратить внимание, что в быту под лояльностью чаще всего понимается отношение «как к своему» по сравнению с тем, как можно было бы отнестись к чужому. Например, начальник ведет себя по отношению к подчиненному «лояльно» (в данном случае снисходительно), если считает его «своим», «лояльно» ведет себя починенный, аналогично относясь к начальнику, что может выражаться в послушании. Их связывают идея общей принадлежности к одной социальной системе, установившиеся взаимоотношения, общая социальная структура, бытующие в ней ценности и цели, составляющие предмет и основу взаимоотношений лояльности, а также конкретные нормы и стереотипы взаимодействия. Быть лояльным также значит следовать принятым в группе нормам, правилам, законам, которые человек считает легитимными для себя и других членов группы. Эти признаки, как правило, и составляют объем бытового понятия лояльности, во всех контекстах его употребления. В русском языке термин «лояльность» в общем смысле обозначает взаимоотношения человека с чем-то или с кем-то, с кем он себя психологически объединяет или связывает на каком-либо основании, и при этом следование нормам и правилам, вытекающим из этой связи. Иногда «лояльность» может обозначать не только фактическое участие в некой системе отношений, но и согласие участвовать в них.

Термин «приверженность» имеет значение, схожее с научным значением термина «commitment», описанным выше, и используется как его аналог (см., например: Магура, 1999). Так же как «верность», «преданность», «привязанность» и т.п., он, в отличие от термина «лояльность», в русском языке характеризует человека скорее как отдельную единицу, чем как часть и типичного 
представителя социальной системы. Как и в английском языке, он, как правило, отражает лишь один или некоторые аспекты отношений человека к объектам социальной среды. И наконец, он ставит человека в центр его социальных отношений, подчеркивая их субъект-объектный характер.

Таким образом, смысловое наполнение слова «лояльность» в бытовом русском языке хотя и не совсем соответствует предложенному содержанию научного термина, но вполне сопоставимо с ним. А слово «приверженность» как в быту, так и в научных исследованиях является практически смысловым эквивалентом термина «commitment», употребленным в этом значении. Таким образом, полученные научные результаты не противоречат сложившейся отечественной практике применения терминов, однако не совпадают с ней полностью, имеют значение для ее корректировки.

С учетом выявленных содержательных отличий и сложившейся практики употребления анализируемых терминов можно дать следующие рекомендации по их научному применению.

1. Термин «лояльность», не имеющий смысла вне отношений человека с конкретной группой его членства, предлагается использовать как специфичный для контекста личностно-групповых взаимоотношений. Применение слова «лояльность» как научного термина целесообразно в ситуациях оценки личностно-группового психоповеденческого соотношения или меры психоповеденческой включенности человека в группу, к которой он принадлежит или имеет какие-либо основания принадлежать. Его применение в других контекстах, в отличие от термина «приверженность», не являющего специфичным для указанной предметной области исследований, предлагается считать недостаточно обоснованным.

2. Термин «лояльность» рекомендуется использовать в ситуациях, когда нужно указать на субъект-субъектный, трансличностный характер связи личности с динамически меняющейся и обладающей рядом объективно сложившихся психоповеденческих характеристик группой, выступающей «коллективным субъектом» (содержание термина см., например: Журавлев, 2009). Если группа, в соотношении с которой оценивается личность, не является групповым (коллективным) субъектом и не имеет объединяющего ее членов психоповеденческого паттерна, обладание которым и определяет членство в группе, применение термина «лояльность» не представляется обоснованным. Термин «приверженность» в социальном контексте, на наш взгляд, можно использовать для обозначения односторонних, субъект-объектных связей личности с группами любого характера, в том числе находящимися на низком уровне социально-психологической интеграции, например, сугубо формальными.

3. Термин «лояльность» целесообразно использовать в отношении группы как целого, подразумевающего всю систему обобщенных характеристик ее членов, а термин «приверженность» - применительно к отдельным характеристикам той или иной группы, например: ее формальным целям, персональному составу, декларируемым или реально доминирующим в группе ценностям, привлекательным жизненным идеям, выгодам, сопутствующим пребыванию в группе, и т.д. Применение термина «лояльность» уместно для 
указания на причастность личности к общегрупповому психоповеденческому паттерну, объединяющему все аспекты включенности личности в группу, все уровни личностно-группового соответствия. Предмет и объект лояльности составляют единое целое. Психоповеденческий паттерн и группа, выступающая его носителем, с позиций лояльности, не мыслятся друг без друга. Использование термина «приверженность» предполагает указание на более простой в психологическом смысле вид связи человека с группой как в плане содержания, так и в плане уровня системной организации ее структурных компонентов.

4. Термин «лояльность» уместнее использовать, чтобы охарактеризовать личность в целом, а термин «приверженность» - чтобы охарактеризовать ее отдельные особенности. Вопрос о приверженности - вопрос об отдельно взятых предпочтениях, ценностях, формах поведения. Вопрос о лояльности равноценен вопросу «Что ты за человек?» и охватывает все элементы и уровни функционирования личности как системы, организованной определенным образом в ходе осуществления ведущей групповой деятельности. Лояльность, в отличие от приверженности, затрагивает всю структуру отношений личности. Приверженность затрагивает личность на уровне отдельных элементов, не влияя на их системные связи и на характеристику личности в целом, не меняя структуру ее ведущих отношений.

5. При описании поведения рекомендуется употреблять термин «лояльность», понимая ее как источник тотальной регуляции поведения в социальной сфере, в которой функционирует группа, или отдельных случаев, выступающих наглядным примером этой тотальной регуляции и подразумевающих ее. Термин «приверженность», на наш взгляд, лучше подходит при описании внутренних причин поступков, связанных с отдельными выборами и решениями человека по частным вопросам, не отражающим направленности личности и социальной самоидентификации. Как правило, приверженность регулирует одно-единственное конкретное действие или аспект поведения например, сохранение членства в группе, потребление определенных продуктов и т.д. в отличие от лояльности, проявляющейся в реализации воспринятой системы групповых принципов и норм правильного поведения во всех аспектах и ситуациях групповой активности. Линия поведения, реализуемая в рамках приверженности, может быть связана с доминирующей мотивацией и направленностью личности опосредованно или не связана вовсе. Поведение, реализуемое в рамках лояльности, непосредственно детерминируется ведущими мотивационными тенденциями и социальной самоидентификацией личности. Термин «приверженность» больше подходит для случаев, в которых для субъекта психологически возможно когнитивное и эмоциональное отделение себя от объекта приверженности, отсутствие самоидентификации с ним.

С учетом указанных отличий термин «приверженность» представляется более актуальным для прикладных исследований, имеющих практические цели оценки, прогнозирования и стимулирования определенных форм поведения. Термин «лояльность» более соответствует концептуальным научным 
исследованиям проблемы личности в группе, отличающимся системностью рассмотрения социально-психологических явлений.

\section{Литература}

Антонова, Н. В. (2017). Внутренний имидж и организационная лояльность в компаниях с разным уровнем социальной защищенности сотрудников. Организационная психология (электронный журнал), 7(2), 66-85. Режим доступа: http://orgpsyjournal.hse.ru

Баранская, С. С. (2012). Психологиеские факторы организащионной лояльности (Кандидатская диссертация). Санкт-Петербургский государственный университет, Санкт-Петербург.

Берлизева, Я. В. (2013). Интегральная модель организационной лояльности персонала. Вестник Кемеровского государственного университета, 2(4), 174-178. doi:10.21603/2078-8975-20134-174-178

Бобрус, О. Н. (2009). Современные подходы к изучению корпоративной лояльности персонала. Ученые записки Российского государственного социального университета, 9, 117-120.

Горностаев, С. В. (2017). Основы психологической теории лояльности. Рязань: РГУ.

Доминяк, В. И. (2006). Организащионная лояльность: модель реализащии ожиданий работника от своей организаиии (Кандидатская диссертация). Санкт-Петербургский государственный университет, Санкт-Петербург.

Журавлев, А. Л. (2009). Коллективный субъект: основные признаки, уровни и психологические типы. Психологический журнал, 30(5), 72-80.

Липатов, С. А. (2004). Проблема организационной приверженности и идентификации с точки зрения социальной психологии. Мир психологии, 2, 142-148.

Лячин, М. А., Подвербных, О. Е. (2017). Лояльность персонала как основа мотивации сотрудников на инновационную активность в организации. Управление человеческими ресурсами основа развития инновационной экономики, 7, 190-196.

Магура, М. И. (1999). Приверженность работников своей организащии (Кандидатская диссертация). Московский государственный университет имени М.В. Ломоносова, Москва.

Серкова, Н. В. (2004). Социально-психологические особенности лояльности и факторы, определяющие ее формирование. Вестник Томского государственного педагогического университета. Серия: Педагогика, 5(42), 131-134.

Стародубцева, Г. А. (2012). Психосемантические составляющие организационной лояльности (Кандидатская диссертация). Ярославский государственный университет, Ярославль.

Трофимова, Е. Л., Бондаренко, В. Ю. (2013). Проблема приверженности персонала к организации в отечественной и зарубежной литературе. Психология в экономике и управлении, 1, 28-36.

Ссылки на зарубежные источники см. в разделе References после англоязычного блока.

Горностаев Станислав Викторович - докторант, Академия ФСИН России, кандидат психологических наук, доцент.

Сфера научных интересов: психологические проблемы работы с персоналом, психология лояльности.

Контакты: stanislavrz@yandex.ru 


\title{
Psychological Meaning, Interrelation and Scientific Applicability of «Loyalty» and «Commitment» Concepts
}

\author{
S.V. Gornostaev ${ }^{\mathrm{a}}$ \\ ${ }^{a}$ Academy of the Federal Penitentiary Service of Russia, 1 Sennaya Str., Ryazan, 390000, Russian \\ Federation
}

\begin{abstract}
The article is devoted to the problem of essential ambiguity and fuzziness of the "loyalty" concept. To solve this problem, the necessity of meaningful differentiation of the concept of "loyalty" with conjugate and related concepts is emphasized. A comparative analysis of the often confused terms "loyalty" and "commitment" is carried out. The possibility of extrapolating the obtained results to the interrelation of the similar Russian terms "loyalty" and "commitment" is analyzed. The following rules for the scientific application of comparable terms are recommended: 1) the term "loyalty" is relevant to use only in the context of personal-group relations, and the term "commitment" - also outside it; 2) the term "loyalty" is applicable only to indicate relations of the "subject-subject" type, which is possible only in the relations of the individual with his membership groups, characterized by real psycho-behavioral unity, and the term "commitment" is applicable for indicating relations of the "subject-object" type as applied to any groups; 3) the term "loyalty" is applicable when considering the relationship of a person with a group as a system in all of its psycho-behavioral aspects taken together, the term "commitment", applied in a person-group context, can reflect a person's attitude to single characteristics of the group; 4) psychologically, the term "loyalty" is more appropriate to use to characterize the person as a whole, and the term "commitment" - to characterize particular features of the person; 5) specifying displays of total regulation of behavior by norms of group, with which there a person identifies himself and forms actual partnership, it is recommended to use the term "loyalty", and the term "commitment" is better suited for describing the actions related to individual choices and decisions of the person not reflecting his orientation and social self-identification. The topicality of the term "loyalty" is noted for systematic conceptual research, which studies person in a group, and the term 'commitment' is important for applied research on specific forms of social behavior.
\end{abstract}

Keywords: loyalty, commitment, social system, group, personality.

\section{References}

Abramson, E., Cutler, H. A., Kautz, R. W., \& Mendelson, M. (1958). Social power and commitment: a theoretical statement. American Sociological Review, 23, 15-22.

Antonova, N. V. (2017). Internal image and loyalty in organizations with different level of social security of employees. Organizational Psychology, 7(2), 66-85. Retrieved from http://orgpsyjournal.hse.ru (in Russian) 
Baranskaya, S. S. (2012). Psikhologicheskie faktory organizatsionnoi loyal'nosti [Psychological factors of organizational loyalty] (PhD dissertation). Saint Petersburg State University, Saint Petersburg, Russian Federation. (in Russian)

Becker, H. S. (1960). Notes on the concept of commitment. American Journal of Sociology, 66(1), 32 40. doi:10.1086/222820

Berlizeva, Y. V. (2013). The integrated model of organizational loyalty. Vestnik Kemerovskogo Gosudarstvennogo Universiteta [Bulletin of Kemerovo State University], 4-2, 174-178. (in Russian)

Bobrus, O. N. (2009). Sovremennye podkhody k izucheniyu korporativnoi loyal'nosti personala [Modern approaches to the study of corporate loyalty personnel]. Uchenye Zapiski Rossiiskogo Gosudarstvennogo Sotsial'nogo Universiteta, 9, 117-120. (in Russian)

Boszormenyi-Nagy, I., \& Spark, G. (1973). Invisible loyalties: reciprocity in intergenerational family Therapy. Hagerstown: Harper \& Row.

Brown, R. B. (1996). Organizational commitment: Clarifying the concept and simplifying the existing construct typology. Journal of Vocational Behavior, 49, 230-251.

Cohen, A. (2003). Multiple commitments in the workplace: An integrative approach. Mahwah, NJ/London: Lawrence Erlbaum Associates Publishers.

Coleman, J. S. (1957). Multidimensional Scale Analysis. American Journal of Sociology, 63(3), 253263. doi:10.1086/222217

Corenblum, A. F. (1964). Loyalty in a formal organization. University of British Columbia. Retrieved from https://open.library.ubc.ca/cIRcle/collections/831/items/1.0102377

Coughlan, R. (2005). Employee loyalty as adherence to shared moral values. Journal of Managerial Issues, 17(1), 43-57.

Dominyak, V. I. (2006). Organizatsionnaya loyal'nost': model' realizatsii ozhidanii rabotnika ot svoei organizatsii [Organizational loyalty: model of realization of expectations of the worker from the organization] (PhD dissertation). Saint Petersburg State University, Saint Petersburg, Russian Federation. (in Russian)

Fletcher, G. P. (1993) Loyalty: an essay on the morality of relationships. Oxford: Oxford University Press.

Fletcher, T. W. (1958). The nature of administrative loyalty. Public Administration Reviere, 18(1), 37 42. doi:10.2307/973733

Fullerton, G. (2003). When does commitment lead to loyalty? Journal of Service Research, 5(4), 333344. doi:10.1177/1094670503005004005

Gornostaev, S. V. (2017). Osnozy psikhologicheskoi teorii loyal'nosti [Fundamentals of the psychological theory of loyalty]. Ryazan: Ryazan State University Publ. (in Russian)

Gouldner, H. P. (1960). Dimensions of organizational commitment. Administrative Science Quarterly, 4(4), 468-490.

Grodzins, M. (1956). The loyal and the disloyal: social boundaries of patriotism and treason. Chicago, IL: The University of Chicago Press.

Iqbal, A., Tufail, M. S., \& Lodhi, R. N. (2015). Employee loyalty and organizational commitment in Pakistani organizations. Global Journal of Human Resource Management, 3(1), 1-11.

Lipatov, S. A. (2004). Problema organizatsionnoi priverzhennosti i identifikatsii s tochki zreniya sotsial'noi psikhologii [The issue of organizational commitment and identification from the perspective of social psychology]. Mir Psikhologii, 2, 142-148. (in Russian)

Lyachin, M. A., \& Podverbnykh, O. E. (2017). Loyal'nost' personala kak osnova motivatsii sotrudnikov na innovatsionnuyu aktivnost' $v$ organizatsii [Personnel loyalty as the basis of motivation of 
employees to innovative activity in the organization]. Upravlenie Chelovecheskimi Resursami Osnova Razvitiya Innovatsionnoi Ekonomiki, 7, 190-196. (in Russian)

Magura, M. I. (1999). Priverzhennost' rabotnikov svoei organizatsii [The commitment of the employees to their organization] (PhD dissertation). Lomonosov Moscow State University, Moscow, Russian Federation.

Maheshwari, V., Lodorfos, G., \& Jacobsen, S. (2014). Determinants of brand loyalty: A study of the experience-commitment-loyalty constructs. International Journal of Business Administration, 5(6), 13-23. doi:10.5430/ijba.v5n6p13

Mayo, B. (1955). Commitments and reasons. Mind, 64(255), 342-360.

Meyer, J. P., \& Allen, N. J. (1997). Commitment in the workplace: Theory, research and application. Thousand Oaks, CA: Sage.

N/A. (1921). Life commitments of college seniors. Christian Education, 4(10), 7-11.

O'Reilly, C. A., \& Chatman, J. (1986). Organizational commitment and psychological attachment: The effects of compliance, identification and internalization on prosocial behavior. Journal of Applied Psychology, 71, 492-499. doi:10.1037/0021-9010.71.3.492

Rogers, A. K. (1918). The philosophy of loyalty. The Journal of Philosophy, Psychology and Scientific Methods, 15(1), 9-22. doi:10.2307/2940573

Royce, J. (1908). The philosophy of loyalty. New York: Macmillan.

Serkova, N. V. (2004). Sotsial'no-psikhologicheskie osobennosti loyal'nosti i faktory, opredelyayushchie ee formirovanie [Socio-psychological specifics of loyalty and factors that determine its formation]. Vestnik Tomskogo Gosudarstvennogo Pedagogicheskogo Universiteta. Seriya: Pedagogika [Tomsk State University Journal. Series: Pedagogy], 5(42), 131-134. (in Russian)

Simon, H. A., Smithburg, D. W., \& Thompson, V. A. (1950). Public administration. New York: Alfred A. Knopf, Inc.

Starodubtseva, G. A. (2012). Psikhosemanticheskie sostavlyayushchie organizatsionnoi loyal'nosti [Psycho-semantic components of organizational loyalty] ( $\mathrm{PhD}$ dissertation). Yaroslavl State University, Yaroslavl, Russian Federation.

Thornberry, P. (2003). Human rights and the shaping of loyalties. In M. Waller \& A. Linklater (Eds.), Political loyalty and the nation-state (pp. 91-104). London/New York: Routledge.

Trofimova, E. L., \& Bondarenko, V. Yu. (2013). The problem of personnel commitment to organization in native and foreign literature. Psikhologiya v Ekonomike i Upravlenii [Psychology in Economics and Management], 1, 28-36. (in Russian)

Von Wright, G. H. (1951). Deontic logic. Mind, 60(237), 1-15.

Zhuravlev, A. L. (2009). Collective subject: Main features, levels and psychological types. Psikhologicheskii Zhurnal, 30(5), 72-80. (in Russian)

Stanislav V. Gornostaev - doctoral student, Academy of the Federal Penitentiary Service of Russia, PhD in Psychology, Associate Professor.

Research Area: psychological problems of HRM, psychology of loyalty.

E-mail: stanislavrz@yandex.ru 